\title{
Challenges of Longevity: Safety of Vaginal and Laparoscopic Urogynecological Procedures in Septuagenarians and Older Patients
}

\author{
R. Joukhadar, ${ }^{1,2}$ A. Wöckel, ${ }^{1}$ D. Herr, ${ }^{1}$ V. Paulus, ${ }^{2}$ J. Radosa, ${ }^{2}$ \\ A. Hamza, ${ }^{2}$ E. Solomayer, ${ }^{2}$ and S. Baum ${ }^{2,3}$ \\ ${ }^{1}$ Department of Obstetrics and Gynecology, University of Würzburg, Würzburg, Germany \\ ${ }^{2}$ Department of Obstetrics and Gynecology, University of Saarland, Homburg, Germany \\ ${ }^{3}$ Department of Obstetrics and Gynecology, University of Schleswig-Holstein, Campus Lübeck, Lübeck, Germany
}

Correspondence should be addressed to R. Joukhadar; joukhadar_r@ukw.de

Received 17 September 2016; Accepted 6 November 2016

Academic Editor: Thorsten Ecke

Copyright (C) 2016 R. Joukhadar et al. This is an open access article distributed under the Creative Commons Attribution License, which permits unrestricted use, distribution, and reproduction in any medium, provided the original work is properly cited.

Introduction. Pelvic organ prolapse (POP) and urinary incontinence (UI) have increasing prevalence in the elderly population. The aim of this study was to compare the comorbidities of these procedures between $<70 \mathrm{y} / \mathrm{o}$ and $\geq 70 \mathrm{y} / \mathrm{o}$ patients. Materials and Methods. In our retrospective study over a period of 2.5 years, 407 patients had received an urogynecological procedure. All patients with POP were treated by reconstructive surgery. Complications were reported using the standardized classification of ClavienDindo (CD). The study can be assigned to stage $2 \mathrm{~b}$ Exploration IDEAL (Idea, Development, Exploration, Assessment, Long-term study)-system of surgical innovation. Results. Operation time, blood loss, and intraoperative complications have not been more frequent in the elderly, whereas hospital stay was significantly longer in $\geq 70 \mathrm{y} / \mathrm{o}$ patients. Regarding postoperative complications, we noticed that $\geq 70 \mathrm{y} / \mathrm{o}$ patients had an almost threefold risk to develop mild early postoperative complications compared to younger patients (OR: 2.86; 95\% CI: 1.76-4.66). On the contrary, major complications were not more frequent. No case of life-threatening complication or the need for blood transfusion was reported. Conclusion. After urogynecological procedures, septuagenarians and older patients are more likely to develop mild postoperative complications but not more intraoperative or severe postoperative complications compared to younger patients.

\section{Introduction}

Both UI and POP are pelvic floor dysfunctions frequently encountered in older women [1]. Recent data revealed high prevalence of both entities with a peak at the age of 70-71 years for UI and a progressively increasing age-specific annual risk for POP [2].

Taking demographic trends into account, it is clear that there is a global significant increase in longevity, which is also to be noticed in Germany $[3,4]$. The greater life expectancy for women leads to a sex ratio increase with age. This trend underpins the inexorably expected growing need for treatment modalities in this population [5].

There seems to be a very negative impact of POP and urinary incontinence on women's quality of life, social behavior, and even their mental status [6, 7]. It is estimated in Germany that up to $50 \%$ of admissions to nursing homes take place for burdens related to urinary incontinence [8].

Although pessaries are not a causal treatment and are often associated with discomfort, their use is still frequent in the elderly $[9,10]$. In many cases, however, surgical correction is the only way to restore anatomy and function. Yet, the elderly are often regarded as unfavorable clientele and are denied access to surgical intervention due to their higher age.

When surgery is performed, obliterative procedures remain more frequently applied $[11,12]$. Yet, evidence suggests the equality and even superiority of reconstructive procedures $[13,14]$.

Although urogynecological surgery in the elderly seems a pressing public health issue, age-related perioperative 
comorbidity especially in reconstructive prolapse surgery is underreported. Our aim was to compare perioperative morbidity in septuagenarians and older patients undergoing surgery with that of younger ones in a retrospective singlecenter study and to estimate the safety of applying reconstructive procedures in the elderly.

\section{Materials and Methods}

2.1. Study Design. We conducted a single-center retrospective study at the University Hospital of Saarland in Homburg, Germany, which is a tertiary referral center for both gynecologic laparoscopy and urogynecology to compare the perioperative morbidities associated with urogynecological procedures regarding the age of patients. Data were collected by reviewing the electronic patient's charts.

All patients who had undergone an operative procedure for treatment of POP or UI between July 2012 and December 2014 were continuously enrolled in this study. In this period of 2.5 years, overall 407 patients were surgically treated. We chose an age cutoff of 70 years and regarded patients $\leq 70$ years as younger, while those aged $\geq 70$ years were regarded as older patients.

Our presented study can be assigned to stage $2 \mathrm{~b}$ Exploration IDEAL (Idea, Development, Exploration, Assessment, Long-term study)-system of surgical innovation. This stage focuses on adverse effects and potential benefits.

2.2. Collected Data. In addition to demographic data, we collected detailed obstetric and surgical history. In order to assess the effect of comorbidities, we chose the American Society of Anesthesiologists' (ASA) risk classification system as an index for the general condition of elderly patients.

We further collected intraoperative data regarding duration of surgery and intraoperative complications as well as postoperative data including hemoglobin $(\mathrm{Hb})$ decline, hospital stay, and the occurrence and type of postoperative complications. We defined $\mathrm{Hb}$ decline as the difference between preoperative $\mathrm{Hb}$ and the lowest $\mathrm{Hb}$ measured during postoperative hospital stay. Details to the evaluation of postoperative complications are presented in Section 2.4.

As for laparoscopies, we regarded the conversion to laparotomy for any reason an intraoperative complication and documented it as such.

2.3. Applied Procedures and Materials. Cases of UI were surgically treated using retropubic and transobturator slings as well as laparoscopic Burch colposuspension. Although technically more challenging, all patients suffering from POP were offered reconstructive procedures. Applied POP surgery can be further subdivided into native tissue repair and meshassisted repair.

There was no need to perform obliterative vaginal surgery or abdominal procedures on the patients enrolled in this study, as they could all be treated with reconstructive vaginal and laparoscopic procedures, which indicates the high standard of treatment.

Vaginal native tissue repair offered included anterior and/or posterior colporrhaphy, McCall culdoplasty procedure, transvaginal sacrospinous fixation, or a combination of these procedures as indicated. Mesh-assisted repair mainly included laparoscopic sacropexy in addition to anterior, posterior, or total vaginal mesh in some selected cases.

Applied mesh material consisted of macroporous type-1 meshes made of polypropylene in most cases and polyvinylidenfluorid (PVDF) in some cases.

2.4. Presentation of Postoperative Complications. Postoperative complications were subdivided into early and intermediate depending on the time of occurrence. Those taking place from leaving the operation room (OR) to $72 \mathrm{~h}$ after discharge were regarded as early complications and those occurring from $72 \mathrm{~h}$ to 30 days after discharge were regarded as intermediate ones. The minimum follow-up time was 30 days after discharge.

We applied the standardized CD classification to record the postoperative complications in this study. This classification provides uniform definitions for the existence and severity of a surgical complication.

Since complications grades CD-I and CD-II represent those managed nonoperatively and only differ in the type of management required, we regarded the sum of both as mild complications. On the other hand, we regarded the sum of complications grade CD-IIIa (complications that required operative management under local anesthesia) and grade CD-IIIb (complications that required operative management under general anesthesia) as severe complications.

We compared the occurrences of postoperative complications for both the early and intermediate time intervals. In each of these intervals, the comparison was undertaken regarding each complication grade on its own (CD-I, CDII, CD-IIIa, and CD-IIIb), as well as regarding the sum of mild (CD-I + CD-II) and that of severe (CD-IIIa + CD-IIIb) complications.

2.5. Statistics. According to the intent-to-treat principle, all patients with evaluable data were analyzed using descriptive statistics. Missing data were not imputed. The null hypothesis of no difference between those younger than 70 years and septuagenarians or older patients receiving urogynecological procedure was exploratively tested against its alternative of any difference.

Categorical variables were tested using chi-square test and Fisher's exact test. Continuous variables were tested using either Student's $t$-test under the assumption of equal variances or Mann-Whitney $U$ test. $p$ values were adjusted on the basis of multiple testing corrections via false discovery rate (FDR) using R(C) Version 3.2.0. Statistical significance was defined as adjusted $p$ value of $\leq 0.05$. The statistical analyses were performed using the program IBM SAS (Version 2.2.; SAS Inc., Cary, NC, USA; http://www.sas.com/). Details are described in Tables 1-6.

Additionally, following predictors were analyzed by logistic regression to assess their impact on postoperative complications: affiliation to the group of $\geq 70 \mathrm{y} / \mathrm{o}$ patients, obesity (Body Mass Index (BMI) > 30), multiparity ( $\geq 3$ births), and ASA score III or IV. All predictors staying significant 
TABLE 1: Patient's characteristics.

\begin{tabular}{|c|c|c|c|c|c|}
\hline Age group (y/o) & $<70$ & & $\geq 70$ & & \\
\hline Parameter & & {$[n]$} & & {$[n]$} & $p$ value \\
\hline Age (y/o) & $55.60 \pm 8.94$ & {$[278]$} & $75.41 \pm 4.05$ & [129] & \\
\hline BMI $\left(\mathrm{kg} / \mathrm{m}^{2}\right)$ & $27.20 \pm 4.72$ & {$[278]$} & $26.97 \pm 4.05$ & [129] & $0.658^{\mathrm{t}}$ \\
\hline ASA score & & {$[278]$} & & {$[128]$} & \\
\hline I & $31(11.2 \%)$ & & $1(0.8 \%)$ & & $0.001^{\mathrm{c}}$ \\
\hline II & $215(77.3 \%)$ & & $78(60.9 \%)$ & & $0.003^{c}$ \\
\hline III & $32(11.5 \%)$ & & $48(37.5 \%)$ & & $<0.001^{\mathrm{c}}$ \\
\hline IV & $0(0.0 \%)$ & & $1(0.8 \%)$ & & $0.401^{\mathrm{f}}$ \\
\hline Birth & $2[1-2]$ & {$[277]$} & $2[2-3]$ & {$[125]$} & $0.032^{\mathrm{m}}$ \\
\hline Vaginal delivery & $2[1-2]$ & [277] & $2[2-3]$ & {$[125]$} & $0.005^{\mathrm{m}}$ \\
\hline C-section & $0[0-0]$ & [277] & $0[0-0]$ & {$[125]$} & $0.006^{\mathrm{m}}$ \\
\hline Vac. extraction & $0[0-0]$ & [277] & $0[0-0]$ & {$[125]$} & $0.098^{\mathrm{m}}$ \\
\hline $\mathrm{BW} \geq 4000 \mathrm{~g}$ & $0[0-0]$ & [277] & $0[0-0]$ & {$[125]$} & $0.628^{\mathrm{m}}$ \\
\hline $\mathrm{BW} \geq 4500 \mathrm{~g}$ & $0[0-0]$ & [277] & $0[0-0]$ & [125] & $0.717^{\mathrm{m}}$ \\
\hline Multiparity $(\geq 3)$ & $68(24.5 \%)$ & [277] & $46(36.8 \%)$ & {$[125]$} & $0.029^{c}$ \\
\hline \multicolumn{6}{|c|}{ Grade IV prolapse (Baden-Walker) for each compartment } \\
\hline Anterior & $30(15.6)$ & {$[192]$} & $34(28.8)$ & {$[118]$} & $0.033^{\mathrm{c}}$ \\
\hline Middle & $11(5.7)$ & {$[192]$} & $28(23.7)$ & {$[118]$} & $<0.001^{\mathrm{c}}$ \\
\hline Posterior & $7(3.6)$ & [192] & $9(7.6)$ & [118] & $0.328^{\mathrm{c}}$ \\
\hline
\end{tabular}

Data are presented as average \pm standard deviation or median and [IQR].

Statistical test: $\mathrm{t}=t$-test; $\mathrm{m}=$ Mann-Whitney $U$ test; $\mathrm{c}=$ chi-squared test; $\mathrm{f}=$ Fischer's exact test.

Vac. extraction: vacuum extraction; BW: birth weight.

TABLE 2: Intraoperative data.

\begin{tabular}{|c|c|c|c|c|c|}
\hline \multirow[t]{2}{*}{ Age group (y/o) } & \multirow[t]{2}{*}{$<70$} & \multicolumn{3}{|c|}{$\geq 70$} & \multirow[b]{2}{*}{$p$ value } \\
\hline & & {$[n]$} & & {$[n]$} & \\
\hline \multicolumn{6}{|l|}{ Duration of surgery (min) } \\
\hline All procedures & $91.06 \pm 65.57$ & [278] & $96.64 \pm 64.35$ & [129] & $0.643^{\mathrm{t}}$ \\
\hline POP procedures & $109.32 \pm 59.75$ & {$[167]$} & $101.24 \pm 60.93$ & {$[110]$} & $0.643^{t}$ \\
\hline UI procedures & $39.84 \pm 35.09$ & {$[86]$} & $33.09 \pm 21.05$ & {$[11]$} & $0.634^{\mathrm{t}}$ \\
\hline Combined procedures & $140[67.50-219.50]$ & {$[25]$} & $60.50[40.75-233.75]$ & {$[8]$} & $0.643^{\mathrm{m}}$ \\
\hline Intraoperative complications & $7(2.5 \%)$ & [278] & $3(2.3 \%)$ & [129] & $1^{\mathrm{f}}$ \\
\hline Bladder injury & $4(57.1 \%)$ & [7] & $2(66.7 \%)$ & [3] & \\
\hline Rectal injury & $1(14.3 \%)$ & {$[7]$} & $0(0.0 \%)$ & {$[3]$} & \\
\hline Uterine perforation & $0(0.0 \%)$ & [7] & $1(33.3 \%)$ & [3] & \\
\hline Emphysema & $1(14.3 \%)$ & [7] & $0(0.0 \%)$ & {$[3]$} & \\
\hline High ventilation pressure & $1(14.3 \%)$ & [7] & $0(0.0 \%)$ & {$[3]$} & \\
\hline
\end{tabular}

Data are presented as average \pm standard deviation or median and [IQR].

Statistical test: $\mathrm{t}=t$-test; $\mathrm{m}=$ Mann-Whitney $U$ test; $\mathrm{f}=$ Fischer's exact test.

TABle 3: Postoperative data.

\begin{tabular}{|c|c|c|c|c|c|}
\hline \multirow[t]{2}{*}{ Age group (y/o) } & $<70$ & \multicolumn{3}{|c|}{$\geq 70$} & \multirow[b]{2}{*}{$p$ value } \\
\hline & & {$[n]$} & & {$[n]$} & \\
\hline Hb decline (g/dL) & $1.13 \pm 0.77$ & [247] & $1.24 \pm 0.89$ & [125] & $0.343^{\mathrm{t}}$ \\
\hline Hospital stay (day) & $5[3.50-7.00]$ & [278] & $6[2.25-8.75]$ & [129] & $<0.001^{\mathrm{m}}$ \\
\hline
\end{tabular}

$\mathrm{Hb}$ : hemoglobin. Data are presented as average \pm standard deviation or median and [IQR].

statistical test: $\mathrm{t}=t$-Test; $\mathrm{m}=$ Mann-Whitney- $U$ test. 
TABLE 4: Detailed presentation of the postoperative complications.

\begin{tabular}{|c|c|c|}
\hline Grade of complication & Age $<70$ & Age $\geq 70$ \\
\hline \multicolumn{3}{|c|}{ Early complications, classified according to CD } \\
\hline \multirow{7}{*}{ I } & (i) Higher need for analgesics: 14 & (i) Higher need for analgesics: 3 \\
\hline & (ii) Prolonged urinary catheterization: 3 & (ii) Prolonged urinary catheterization: 4 \\
\hline & (iii) Requiring iv. fluids: 2 & (iii) Requiring iv. fluids: 1 \\
\hline & (iv) Requiring vaginal tamponade: 1 & (iv) Requiring vaginal tamponade: 2 \\
\hline & (v) Prolonged hospital stay: 1 & (v) Prolonged hospital stay: 2 \\
\hline & (vi) Requiring observation in ICU: 3 & (vi) Transient paresthesia: 1 \\
\hline & $\begin{array}{l}\text { (vii) Requiring drugs for temporary symptomatic } \\
\text { treatment: } 3\end{array}$ & $\begin{array}{l}\text { (vii) Requiring drugs for temporary symptomatic } \\
\text { treatment: } 3\end{array}$ \\
\hline \multirow{3}{*}{ II } & (i) Requiring antibiotics: 21 & (i) Requiring antibiotics: 21 \\
\hline & (ii) Requiring antihypertensives: 6 & (ii) Requiring antihypertensives: 21 \\
\hline & $\begin{array}{l}\text { (iii) Requiring other drugs for temporary symptomatic } \\
\text { treatment: } 10\end{array}$ & $\begin{array}{l}\text { (iii) Requiring other drugs for temporary symptomatic } \\
\text { treatment: } 8\end{array}$ \\
\hline \multirow{4}{*}{ IIIa } & Performed under local anesthesia & Performed under local anesthesia \\
\hline & (i) Loosening a tight TVT sling: 6 & (i) Loosening a tight TVT sling: 3 \\
\hline & (ii) Revision of a vaginal hematoma: 1 & (ii) Revision of a vaginal hematoma: 1 \\
\hline & & (iii) Suture of a scar dehiscence: 1 \\
\hline \multirow{5}{*}{ IIIb } & Performed under general anesthesia & Performed under general anesthesia \\
\hline & (i) Revision of a colporrhaphy scar: 4 & (i) Revision of a colporrhaphy scar: 1 \\
\hline & (ii) Loosening a colposuspension suture: 1 & (ii) Revision of a vaginal suture: 1 \\
\hline & (iii) Loosening a sacropexy mesh: 1 & \\
\hline & (iv) Revision of a rectal suture: 1 & \\
\hline \multicolumn{3}{|c|}{ Intermediate complications, classified according to CD } \\
\hline \multirow{3}{*}{ I } & (i) Higher need for analgesics: 1 & (i) Observation/minor scar dehiscence: 1 \\
\hline & (ii) Observation/minor scar dehiscence: 1 & \\
\hline & (iii) Observation/minor urinary retention: 1 & \\
\hline \multirow{2}{*}{ II } & (i) Requiring antibiotics: 8 & (i) Requiring antibiotics: 9 \\
\hline & $\begin{array}{l}\text { (ii) Requiring drugs for temporary symptomatic } \\
\text { treatment: } 4\end{array}$ & $\begin{array}{l}\text { (ii) Requiring drugs for temporary symptomatic } \\
\text { treatment: } 3\end{array}$ \\
\hline \multirow{3}{*}{ IIIa } & Procedures performed under local anesthesia & \\
\hline & (i) Draining a labial boil: 1 & \\
\hline & (ii) Loosening a tight TVT sling: 3 & \\
\hline \multirow{4}{*}{ IIIb } & Performed under general anesthesia & Procedures performed under general anesthesia \\
\hline & (i) Revision of a hematoma: 1 & (i) Revision of a hematoma: 1 \\
\hline & (ii) Laparoscopic ureterolysis: 1 & \\
\hline & (iii) Loosening a colposuspension suture: 1 & \\
\hline
\end{tabular}

( $p<0.05)$ after adjusting for multiple testing have been additionally analyzed in a multivariate model.

\section{Results}

3.1. Patient's Characteristics. Out of 407 patients who had undergone a surgical treatment for POP, urinary incontinence, or both, $278(68.3 \%)$ were younger than $70 \mathrm{y} / \mathrm{o}$, whereas $129(31.7 \%)$ were aged 70 years or older.

The preoperative general health condition of septuagenarians and older patients was significantly worse compared with younger patients. Older patients more frequently were classified ASA-III (37.5\% versus 11.5\%; $p<0.001$ ) (Table 1).
There were no significant differences regarding BMI. Differences regarding obstetrical history are presented in detail in Table 1.

3.2. Intraoperative Data. No significant differences could be found between both age groups regarding duration of surgery or the occurrence of intraoperative complications (Table 2).

Overall intraoperative complications occurred in $2.5 \%$ of the younger patients and in $2.3 \%$ of the septuagenarians and older patients. Most of these complications seemed to be occurring sporadically without any tendency for repetition except for the bladder injury which was the most common intraoperative complication in both groups (Table 2). 
TABle 5: Postoperative complications classified according to Clavien-Dindo.

\begin{tabular}{|c|c|c|c|c|c|c|}
\hline \multirow[b]{2}{*}{ Grade } & \multicolumn{3}{|c|}{ Minor complications } & \multicolumn{3}{|c|}{ Major complications } \\
\hline & I & II & $(\mathrm{I}+\mathrm{II})$ & IIIa & IIIb & (IIIa + IIIb) \\
\hline \multicolumn{7}{|l|}{ Early compl. } \\
\hline Age $<70$ & $27(9.7 \%)$ & $34(12.2 \%)$ & $61(21.9 \%)$ & $7(2.5 \%)$ & $7(2.5 \%)$ & $14(5.0 \%)$ \\
\hline Age $\geq 70$ & $16(12.4 \%)$ & $47(36.4 \%)$ & $63(48.8 \%)$ & $5(3.9 \%)$ & $2(1.6 \%)$ & $7(5.4 \%)$ \\
\hline p value & $0.796^{c}$ & $<0.001^{\mathrm{c}}$ & $<0.001^{\mathrm{c}}$ & $0.796^{\mathrm{f}}$ & $0.967^{\mathrm{f}}$ & $1^{\mathrm{c}}$ \\
\hline \multicolumn{7}{|l|}{ Late compl. } \\
\hline Age $<70$ & $3(1.1 \%)$ & $12(4.3 \%)$ & $15(5.4 \%)$ & $4(1.4 \%)$ & $3(1.1 \%)$ & $7(2.5 \%)$ \\
\hline Age $\geq 70$ & $1(0.8 \%)$ & $12(9.3 \%)$ & $13(10.1 \%)$ & $0(0.0 \%)$ & $1(0.8 \%)$ & $1(0.8 \%)$ \\
\hline p value & $1^{\mathrm{f}}$ & $0.272^{\mathrm{c}}$ & $0.281^{\mathrm{c}}$ & $0.749^{\mathrm{f}}$ & $1^{\mathrm{f}}$ & $0.796^{\mathrm{f}}$ \\
\hline
\end{tabular}

Early compl.: early complications from leaving the OR until $72 \mathrm{hrs}$ after discharge from hospital; late compl.: late complications occurring from $72 \mathrm{hrs}$ until 30 days after discharge from hospital.

Statistical test: $\mathrm{c}=$ chi-squared test $\mathrm{f}=$ Fischer's exact test.

TABLE 6: Postoperative complications: logistic regression and multivariate analysis.

\begin{tabular}{|c|c|c|c|c|}
\hline & $\begin{array}{c}p \text { value } \\
\text { Univariate analysis }\end{array}$ & $\begin{array}{c}p \text { value } \\
\text { Multivariate analysis }\end{array}$ & OR & $95 \% \mathrm{CI}$ \\
\hline \multicolumn{5}{|c|}{ Early postoperative complications } \\
\hline Age group ${ }^{1}$ & $<0.001$ & $<0.001$ & 2.953 & $1.893-4.607$ \\
\hline BMI & 0.543 & & 1.014 & $0.970-1.060$ \\
\hline Multiparity $^{2}$ & 0.005 & 0.035 & 1.746 & $1.102-2.769$ \\
\hline ASA score ${ }^{3}$ & 0.002 & 0.140 & 1.560 & $0.912-2.669$ \\
\hline \multicolumn{5}{|c|}{ Mild early complications } \\
\hline Age group ${ }^{1}$ & $<0.001$ & $<0.001$ & 2.862 & $1.757-4.661$ \\
\hline BMI & 0.388 & & 1.021 & $0.974-1.070$ \\
\hline Multiparity $^{2}$ & 0.005 & 0.046 & 1.765 & $1.082-2.880$ \\
\hline ASA score ${ }^{3}$ & $<0.001$ & 0.064 & 1.748 & $1.004-3.043$ \\
\hline \multicolumn{5}{|c|}{ Severe early complications } \\
\hline Age group ${ }^{1}$ & 0.627 & & 1.720 & $0.664-4.459$ \\
\hline BMI & 0.782 & & 0.971 & $0.873-1.079$ \\
\hline Multiparity $^{2}$ & 0.627 & & 1.631 & $0.630-4.224$ \\
\hline ASA score ${ }^{3}$ & 0.935 & & 0.949 & $0.267-3.374$ \\
\hline \multicolumn{5}{|c|}{ Intermediate postoperative complications } \\
\hline Age group ${ }^{1}$ & 0.666 & & 1.417 & $0.700-2.868$ \\
\hline BMI & 0.674 & & 1.025 & $0.953-1.103$ \\
\hline Multiparity $^{2}$ & 0.799 & & 0.902 & $0.407-1.996$ \\
\hline ASA score ${ }^{3}$ & 0.666 & & 0.476 & $0.163-1.386$ \\
\hline \multicolumn{5}{|c|}{ Mild intermediate complications } \\
\hline Age group ${ }^{1}$ & 0.385 & & 1.929 & $0.889-4.186$ \\
\hline BMI & 0.784 & & 1.023 & $0.942-1.112$ \\
\hline Multiparity $^{2}$ & 0.086 & & 0.923 & $0.377-2.260$ \\
\hline ASA score $^{3}$ & 0.784 & & 0.634 & $0.214-1.882$ \\
\hline \multicolumn{5}{|c|}{ Severe intermediate complications } \\
\hline Age group ${ }^{1}$ & 0.997 & & 0.318 & $0.039-2.615$ \\
\hline BMI & 0.997 & & 1.033 & $0.891-1.198$ \\
\hline Multiparity $^{2}$ & 0.997 & & 0.835 & $0.166-4.203$ \\
\hline ASA score ${ }^{3}$ & 0.997 & & 0.000 & \\
\hline
\end{tabular}

OR: odds ratio; CI: Confidence Interval.

ASA score: for the logistic regression we summed up ASA I + II as well as ASA III + IV.

1 = Reference: age $<70$ y/o; 2 = Reference: $<3$ births; 3 = Reference: ASA I + II.

$p$ value was adjusted to "FDR." 


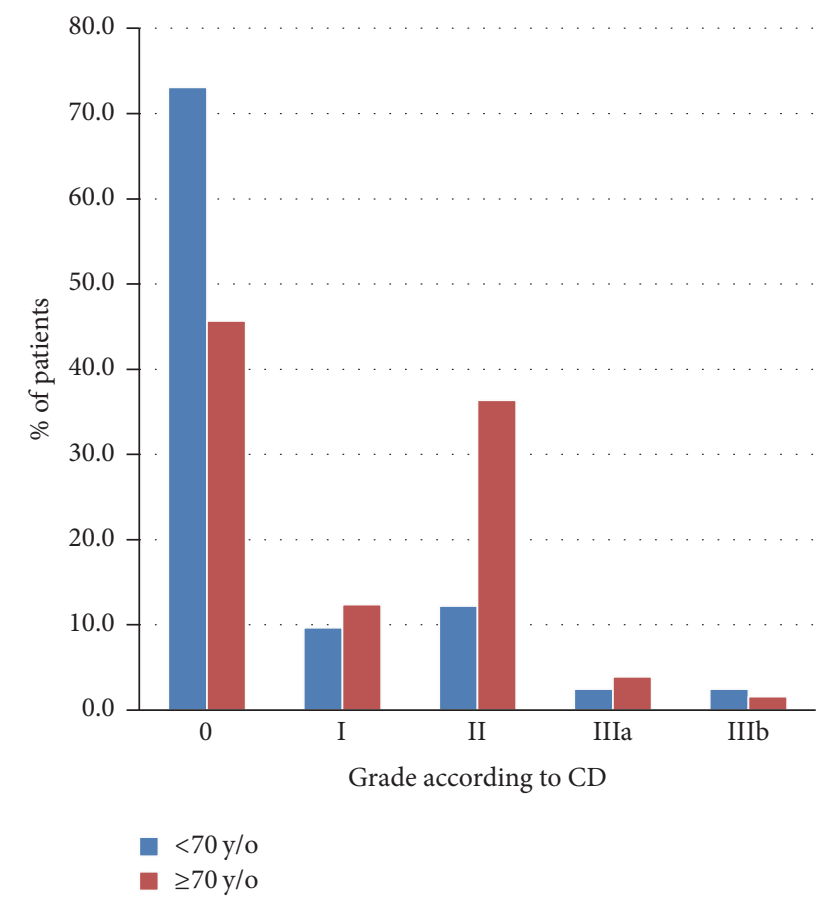

Figure 1: Early postoperative complications.

3.3. Postoperative Data. Regarding $\mathrm{Hb}$ decline, there was no significant difference between both age groups, whereas hospital stay was significantly longer in septuagenarians and older patients (Table 3).

3.4. Postoperative Complications. The postoperative complications were recorded using the CD classification and categorized into CD-I, CD-II, CD-IIIa, and CD-IIIb. No complication severity in this study reached higher than stage CD-IIIb. A detailed presentation of the postoperative complications can be found in Table 4 .

We found that $\geq 70 \mathrm{y} / \mathrm{o}$ patients suffered significantly more frequently from mild postoperative complications, which was mainly attributed to the occurrence of grade CD-II. No significant differences, however, could be found concerning severe complications.

The incidence of early complications grade CD-II in $\geq 70$ y/o patients was higher compared with younger patients (36.4\% versus $12.2 \% ; p<0.001)$. Further significant differences were found regarding the sum of early mild complications (48.8\% versus $21.9 \%$; $p<0.001$ ) (Table 5) (Figure 1).

On the contrary, we found that neither mild nor severe intermediate postoperative complications were more frequent in septuagenarians and older patients (Table 5) (Figure 2).

Four parameters have further been analyzed by a logistic regression to assess their impact on postoperative complications. Of those four, the following three showed significant results: affiliation to the group of $\geq 70 \mathrm{y} / \mathrm{o}$ patients, multiparity ( $\geq 3$ births), and having an ASA score III or IV $(p<$ $0.05)$. With regard to the resulting odds ratio, the group of

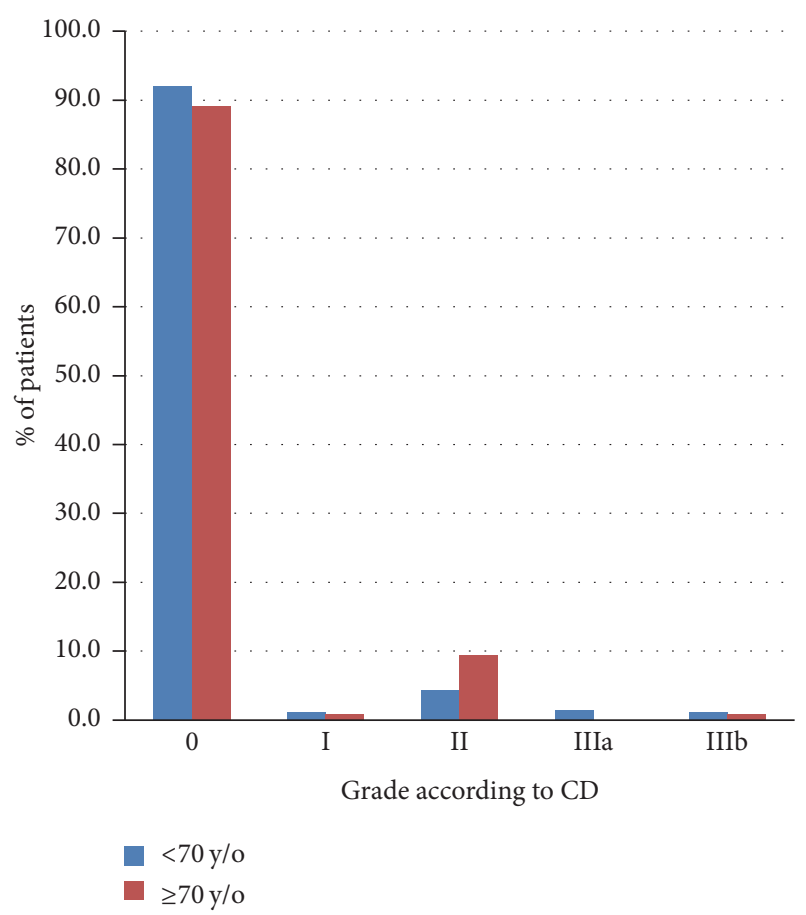

FIGURE 2: Late postoperative complications.

$\geq 70 \mathrm{y} / \mathrm{o}$ patients had an almost threefold risk to develop early postoperative complications as compared to the group of younger patients (OR: 2.95; 95\% CI: 1.89-4.61). However, the influence of multiparity was slightly less (OR: 1.75; 95\% CI: 1.11-2.77) (Table 6).

Further differentiating the early complications into the two subgroups, mild and severe early postoperative complications revealed the fact that both affiliation to the elderly group (OR: 2.86; 95\% CI: 1.76-4.66) and multiparity (OR: 1.77; 95\% CI: 1.08-2.88) were significant predictors for the mild early postoperative complications.

None of the predictors showed a significant correlation to the occurrence of intraoperative complications, mild intermediate postoperative complications, or any severe postoperative complication (Table 6).

\section{Discussion}

Demographic data from Germany show that the proportion of people $\geq 65 \mathrm{y} / \mathrm{o}$ will rise from $21 \%$ in 2015 to an estimated $33 \%$ in 2060. Along with rising life expectancy, these trends are expected to increase the future need for urogynecological surgery [4].

Our contemporary data analysis shows that UI and POP in the elderly patients aged $\geq 70$ years can be safely managed surgically and that, even in cases of total prolapse, reconstructive procedures can be applied with good outcome. Our choice of the age cutoff is based on the definition of geriatric patients in Germany, which is acknowledged to be a patient aged $\geq 70 \mathrm{y} / \mathrm{o}$ in addition to suffering from defined health burdens [15]. 
The percentage of $\geq 70 \mathrm{y} / \mathrm{o}$ patients in our study was impressively high compared with other studies with the same age cutoff ( $31.7 \%$ versus $21 \%, 18.8 \%$, and $20.6 \%$, resp.), which further underpins the study results [16-18].

Septuagenarians and older patients suffered significantly more often from a reduced general condition than the younger ones. Up to $38 \%$ of the elderly in our study had an ASA score of III-IV, yet they were offered the same surgical options as younger patients including reconstructive POP procedures.

We did not find significant differences concerning duration of surgery between both age groups, which was in consistence with data from previous studies $[19,20]$. The occurrence of intraoperative complications also did not significantly differ between the age groups. This also seemed to agree with other studies $[17,19,20]$.

The intraoperative complications in our study seemed to be sporadic occurring only once except for bladder injury which occurred in 6 patients of whom all had received a laparoscopic sacropexy. The incidence of bladder injury during laparoscopic sacropexy in our study was 6/104 (5.7\%), which lays within the upper accepted range when compared with other studies $[21,22]$. Amongst overall low incidence of complications in our study, this may be explained by the very low rate of conversion to laparotomy for technical difficulty in our study in comparison with reported rates in other studies (0\% versus $1.9-4.6 \%)$ [21-23].

In order to evaluate surgical blood loss during surgery, we chose $\mathrm{Hb}$ decline rather than estimated blood loss for comparison, since it is less observer-dependent. Our data show low $\mathrm{Hb}$ decline in both age groups and no difference between them.

Hospital stay was significantly longer in $\geq 70 \mathrm{y} / \mathrm{o}$ patients than in the younger ones, which was in consistence with other studies $[16,18,19]$. Yet, a possible confounder in discharging elderly patients is one of logistic nature, like waiting for discharge solutions or assistance from social workers [24].

Age-dependent occurrence of postoperative complications after urogynecological procedures is controversially discussed in literature. Although fairly consistent in that a comparable anatomical outcome can be achieved, studies seem controversial with regard to postoperative complications. Whereas some showed no differences $[16,17,25,26]$, others had proven that elderly patients suffered significantly from more postoperative complications than the younger ones [18-20,27].

In an effort to clarify this issue, we applied a very strict protocol for recording complications in which we defined a complication as any deviation whatsoever from the ideal perioperative course without judging the causality. Classifying complications according to CD is acknowledged in urogynecology and even recommended by medical societies [28-32].

The most prevalent complications grade CD-I were higher need for analgesics and prolonged urinary catheterization due to temporary urinary retention. Both occurred mainly as early complication. Since registration of higher need for analgesics requires a standardized postoperative pain management, it was not reported as a complication in most studies [18-20].

Regarding complications grade CD-II, the most prevalent ones were requirement of antibiotics and requirement of antihypertensives. The requirement of antibiotics in our study resulted in most cases from urinary tract infections (UTIs) which were detected postoperatively in $10 \%$ of $\geq 70 \mathrm{y} / \mathrm{o}$ patients and in $6.5 \%$ of the younger ones. This high prevalence of postoperative UTIs in urogynecological patients is in consistence with data from other studies [33].

Nevertheless, it has to be mentioned that we had performed a urinalysis in each operated patient on the first postoperative day during the removing of the indwelling catheter. Thus, the detection rate was very accurate even in asymptomatic patients. In their study, Sze at al. came to similar results [17].

The requirement of antihypertensives, which made up for the most obvious difference between both age groups, was solely underreported in most studies [17-20]. In a further evaluation of our clientele, we found that all the $\geq 70 \mathrm{y} / \mathrm{o}$ patients who had required antihypertensives postoperatively were known to suffer from hypertension preoperatively. These patients were already taking antihypertensive medication and experienced a rising need postoperatively, so that either the dosage of the patient's home medication had to be increased or an additional pharmacological substance is added.

Most of the mild complications in the elderly seem to be attributed to the preoperative comorbidity and reduced patient's mobility.

Comparing previously published data with our results is hampered by the lack of uniform methodology. Just to mention the age cutoff set for comparison, the definition of complications, and their classification, the follow-up time and the vast differences concerning the applied surgical procedures are only some differences that cannot be overcome.

The strengths of this study include the high percentage of $\geq 70 \mathrm{y} / \mathrm{o}$ patients compared with other studies, which further reaffirms the study results [16-18].

Another strength is the high ratio of reconstructive surgery of POP, which is technically more challenging but has anatomical and functional advantages towards obliterative procedures, which are more frequently applied in the elderly [11-14]. Thus, the data from our study encourage offering reconstructive procedures to elderly patients.

A further strength is that the study concerns the assignment to stage 2b Exploration IDEAL-system of surgical innovation. According to the definitions of the stages that were further explained on the website of the "IDEAL collaboration," this stage involves data from studies with an output concerning measurement and comparison and focuses on adverse effects and potential benefits. Regarding the number of patients, it is stated that this stage has to involve many rather than few, and the number of surgeons is defined as many, too. In our study, we had involved more than 400 patients who were treated surgically by 4 surgeons.

The type of patients in the studies assigned to this stage $2 \mathrm{~b}$ should be a mixed type with broadening of the indication. Our study seems to fulfill this requirement too, as the 
complete spectrum of accepted and standardized vaginal and laparoscopic reconstructive surgery was applied in our study. Our innovation concerned the application in a highly aged group of patients who are routinely denied access to these procedures because of lack of experience in the outcome in this age group [34, 35].

Concerning follow-up, stage $2 \mathrm{~b}$ Exploration only requires short-term or patient-reported outcomes in opposition to stage 3 Assessment which requires middle-term and stage 4 which requires long-term outcomes. Although our study presents middle-term outcomes, it cannot be assigned to stage 3 Assessment, since either randomized clinical trials or multicenter data are required for this stage, which our data do not fulfil $[34,35]$.

Lastly, the study had continuously enrolled all performed procedures in this tertiary center without any exclusion criteria and the complications were recorded following a very strict and standardized protocol, leaving very little room for observer's interpretation.

But our study also had several limitations. The character of a monocentric case-control study implements a bias in the retrospective nature of data acquisition from possibly inhomogeneous documentation.

Another limitation is that patients were not randomized to the different procedures. It has rather to be said that the selection of the procedure for each patient was based on many criteria including age, which, in addition to the extent of the disease, patient's surgical history, and weight, was an important factor in decision making.

Lastly, there is a limitation regarding follow-up. All patients in whom an alloplastic material was applied during surgery were offered a follow-up at 3-6 months after discharge. This group of patients comprised $74.7 \%$ of whom almost 95\% participated in follow-up. The remaining 5\% were inquired by telephone. As for patients who had undergone native tissue repair, we assume that they would have sought treatment in our center in case of postoperative complications, since the hospital was the only regional tertiary center for urogynecology. Yet we can only be sure that the vast majority but not all possible complications are known to us.

In order to gain more valuable information about applying urogynecological surgery in the very aged, efforts should be undertaken to perform multicenter studies or randomized controlled studies to fulfil the requirements for assignment to stage 3 Assessment of IDEAL-system of surgical innovation. One further necessity seems to be constructing registries for further structured long-term follow-up and subgroup analysis according to IDEAL stage 5 .

\section{Conclusion}

Even though the general health condition was significantly worse and the extent of prolapse was significantly higher in septuagenarians and older compared with younger patients, they were offered the same therapeutic options and treated using reconstructive POP surgery. Neither operation time nor blood loss or intraoperative complications were more frequent in $\geq 70 \mathrm{y} / \mathrm{o}$ patients, whereas hospital stay was significantly longer.
Regarding postoperative complications, we noticed that minor complications had occurred more frequently in $\geq 70$ y/o patients who had an almost threefold risk to develop mild early postoperative complications compared with younger patients (OR: 2.86; 95\% CI: 1.76-4.66). On the contrary, major complications were not more frequent. No case of life-threatening complication or the need for intensive care or blood transfusion was reported.

We advise that elderly patients with the need for urogynecological procedures should be offered all surgical options and counseled about a higher risk to develop minor but not major complications.

We advise to perform multicenter studies and to build up registries for further structured long-term follow-up and subgroup analysis.

\section{Abbreviations \\ ASA: American Society of Anesthesiologists \\ BMI: Body Mass Index \\ CD: Clavien-Dindo \\ FDR: False discovery rate \\ Hb: Hemoglobin \\ IDEAL: Idea, Development, Exploration, \\ OR: Operation room \\ POP: Pelvic organ prolapse \\ UI: $\quad$ Urinary incontinence \\ UTI: Urinary tract infection.}

\section{Competing Interests}

The authors declare that there are no competing interests regarding the publication of this paper.

\section{References}

[1] A. Tinelli, A. Malvasi, S. Rahimi et al., "Age-related pelvic floor modifications and prolapse risk factors in postmenopausal women," Menopause, vol. 17, no. 1, pp. 204-212, 2010.

[2] J. M. Wu, C. A. Matthews, M. M. Conover, V. Pate, and M. Jonsson Funk, "Lifetime risk of stress urinary incontinence or pelvic organ prolapse surgery," Obstetrics and Gynecology, vol. 123, no. 6, pp. 1201-1206, 2014.

[3] United Nations, "Population ageing and development. 2009," http://www.unpopulation.org.

[4] Statistisches Bundesamt, Bevölkerung Deutschlands bis 2060, 13. koordinierte Bevölkerungsvorausberechnung, 2015, https:// www.destatis.de/DE/Publikationen/Thematisch/Bevoelkerung/VorausberechnungBevoelkerung/BevoelkerungDeutschland2060Presse5124204159004.pdf?__blob=publicationFile.

[5] J. Pizarro-Berdichevsky, M. M. Clifton, and H. B. Goldman, "Evaluation and management of pelvic organ prolapse in elderly women," Clinics in Geriatric Medicine, vol. 31, no. 4, pp. 507-521, 2015.

[6] G. A. Digesu, C. Chaliha, S. Salvatore, A. Hutchings, and V. Khullar, "The relationship of vaginal prolapse severity to symptoms and quality of life," BJOG: An International Journal of Obstetrics and Gynaecology, vol. 112, no. 7, pp. 971-976, 2005. 
[7] C.-H. Chiang, M.-P. Wu, C.-H. Ho et al., "Lower urinary tract symptoms are associated with increased risk of dementia among the elderly: a nationwide study," BioMed Research International, vol. 2015, Article ID 187819, 7 pages, 2015.

[8] A. Welz-Barth, "Incontinence in old age. A social and economic problem," Urologe A, vol. 46, no. 4, pp. 363-367, 2007.

[9] S. C. de Albuquerque Coelho, E. B. de Castro, and C. R. Juliato, "Female pelvic organ prolapse using pessaries: systematic review," International Urogynecology Journal, vol. 27, no. 12, pp. 1797-1803, 2016.

[10] C. M. Panman, M. Wiegersma, B. J. Kollen, H. Burger, M. Y. Berger, and J. H. Dekker, "Predictors of unsuccessful pessary fitting in women with prolapse: a cross-sectional study in general practice," International Urogynecology Journal, 2016.

[11] A. J. Hill, M. D. Walters, and C. A. Unger, "Perioperative adverse events associated with colpocleisis for uterovaginal and posthysterectomy vaginal vault prolapse," American Journal of Obstetrics and Gynecology, vol. 214, no. 4, pp. 501.e1-501.e6, 2016.

[12] A. N. Alas and J. T. Anger, "Management of apical pelvic organ prolapse," Current Urology Reports, vol. 16, no. 5, p. 33, 2015.

[13] M. Murphy, G. Sternschuss, R. Haff, H. van Raalte, S. Saltz, and V. Lucente, "Quality of life and surgical satisfaction after vaginal reconstructive vs obliterative surgery for the treatment of advanced pelvic organ prolapse," American Journal of Obstetrics and Gynecology, vol. 198, no. 5, pp. 573.el-573.e7, 2008.

[14] S. A. Collins, J. E. Jelovsek, C. C. G. Chen, A. M. Gustilo-Ashby, and M. D. Barber, "De novo rectal prolapse after obliterative and reconstructive vaginal surgery for urogenital prolapse," American Journal of Obstetrics and Gynecology, vol. 197, no. 1, pp. 84.e1-84.e3, 2007.

[15] M. Borchelt, G. Kolb, N. Lübke, and D. Lüttje, Abgrenzungskriterien der Geriatrie. Version V1.3. Essener Konsensus-Konferenz, 2004.

[16] H. E. Richter, P. S. Goode, K. Kenton et al., "The effect of age on short-term outcomes after abdominal surgery for pelvic organ prolapse," Journal of the American Geriatrics Society, vol. 55, no. 6, pp. 857-863, 2007.

[17] E. H. M. Sze, P. Jain, and G. Hobbs, "A retrospective cohort study of perioperative management on the morbidity of urogynecologic surgery," International Urogynecology Journal, vol. 23, no. 9, pp. 1207-1214, 2012.

[18] V. W. Sung, S. Weitzen, E. R. Sokol, C. R. Rardin, and D. L. Myers, "Effect of patient age on increasing morbidity and mortality following urogynecologic surgery," American Journal of Obstetrics and Gynecology, vol. 194, no. 5, pp. 1411-1417, 2006.

[19] C. E. Bretschneider, B. Robinson, E. J. Geller, and J. M. $\mathrm{Wu}$, "The effect of age on postoperative morbidity in women undergoing urogynecologic surgery," Female Pelvic Medicine and Reconstructive Surgery, vol. 21, no. 4, pp. 236-240, 2015.

[20] L. C. Turner, K. Kantartzis, J. L. Lowder, and J. P. Shepherd, “The effect of age on complications in women undergoing minimally invasive sacral colpopexy," International Urogynecology Journal and Pelvic Floor Dysfunction, vol. 25, no. 9, pp. 1251-1256, 2014.

[21] A. W. Coolen, A. M. van Oudheusden, H. W. van Eijndhoven et al., "A comparison of complications between open abdominal sacrocolpopexy and laparoscopic sacrocolpopexy for the treatment of vault prolapse," Obstetrics and Gynecology International, vol. 2013, Article ID 528636, 7 pages, 2013.
[22] C. A. Unger, M. F. R. Paraiso, J. E. Jelovsek, M. D. Barber, and B. Ridgeway, "Perioperative adverse events after minimally invasive abdominal sacrocolpopexy," American Journal of Obstetrics and Gynecology, vol. 211, no. 5, pp. 547.e1-547.e8, 2014.

[23] R. K. Lee, A. Mottrie, C. K. Payne, and D. Waltregny, "A review of the current status of laparoscopic and robot-assisted sacrocolpopexy for pelvic organ prolapse," European Urology, vol. 65, no. 6, pp. 1128-1137, 2014.

[24] V. Parent, S. Ludwig-Béal, H. Sordet-Guépet et al., "Prolonged stays in hospital acute geriatric care units: identification and analysis of causes," Gériatrie et Psychologie Neuropsychiatrie du Vieillissement, vol. 14, no. 2, pp. 135-141, 2016.

[25] S. Oh, S. H. Shin, J. Y. Kim, M. Lee, and M. J. Jeon, "Perioperative and postoperative morbidity after sacrocolpopexy according to age in Korean women," Obstetrics \& Gynecology Science, vol. 58, no. 1, pp. 59-64, 2015.

[26] Y. L. Tan, T.-S. Lo, S. Khanuengkitkong, and A. K. Dass, "Comparison of outcomes after vaginal reconstruction surgery between elderly and younger women," Taiwanese Journal of Obstetrics and Gynecology, vol. 53, no. 3, pp. 348-354, 2014.

[27] H. Pugsley, C. Barbrook, C. J. Mayne, and D. G. Tincello, "Morbidity of incontinence surgery in women over 70 years old: A Retrospective Cohort Study," BJOG: An International Journal of Obstetrics and Gynaecology, vol. 112, no. 6, pp. 786-790, 2005.

[28] D. Dindo, N. Demartines, and P.-A. Clavien, "Classification of surgical complications: a new proposal with evaluation in a cohort of 6336 patients and results of a survey," Annals of Surgery, vol. 240, no. 2, pp. 205-213, 2004.

[29] R. Joukhadar, G. Meyberg-Solomayer, A. Hamza et al., "A novel operative procedure for pelvic organ prolapse utilizing a MRIvisible mesh implant: safety and outcome of modified laparoscopic bilateral sacropexy," BioMed Research International, vol. 2015, Article ID 860784, 9 pages, 2015.

[30] A. R. Mothes, M. P. Radosa, and I. B. Runnebaum, "Systematic assessment of surgical complications in laparoscopically assisted vaginal hysterectomy for pelvic organ prolapse," European Journal of Obstetrics Gynecology and Reproductive Biology, vol. 194, pp. 228-232, 2015.

[31] D. Barski, T. Otto, and H. Gerullis, "Systematic review and classification of complications after anterior, posterior, apical, and total vaginal mesh implantation for prolapse repair," Surgical Technology International, vol. 24, pp. 217-224, 2014.

[32] D. Mitropoulos, W. Artibani, M. Graefen, M. Remzi, M. Rouprêt, and M. Truss, "Reporting and grading of complications after urologic surgical procedures: an ad hoc eau guidelines panel assessment and recommendations," Actas Urologicas Espanolas, vol. 37, no. 1, pp. 1-11, 2013.

[33] G. Sutkin, M. Alperin, L. Meyn, H. C. Wiesenfeld, R. Ellison, and H. M. Zyczynski, "Symptomatic urinary tract infections after surgery for prolapse and/or incontinence," International Urogynecology Journal, vol. 21, no. 8, pp. 955-961, 2010.

[34] P. McCulloch, D. G. Altman, W. B. Campbell et al., "No surgical innovation without evaluation: the IDEAL recommendations," The Lancet, vol. 374, no. 9695, pp. 1105-1112, 2009.

[35] A. Sedrakyan, B. Campbell, J. G. Merino, R. Kuntz, A. Hirst, and P. McCulloch, "IDEAL-D: a rational framework for evaluating and regulating the use of medical devices," The British Medical Journal, vol. 353, Article ID i2372, 2016. 


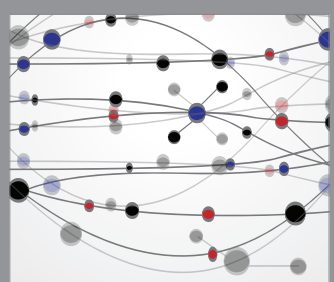

The Scientific World Journal
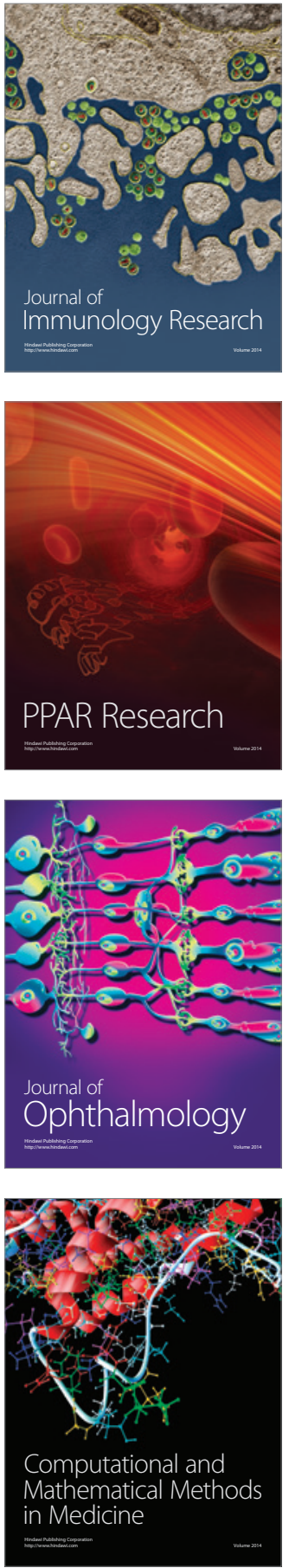

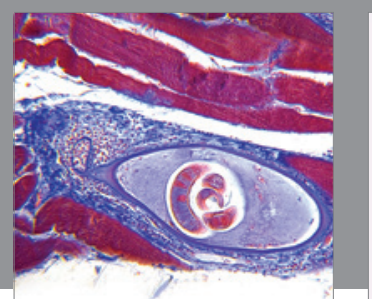

Gastroenterology Research and Practice

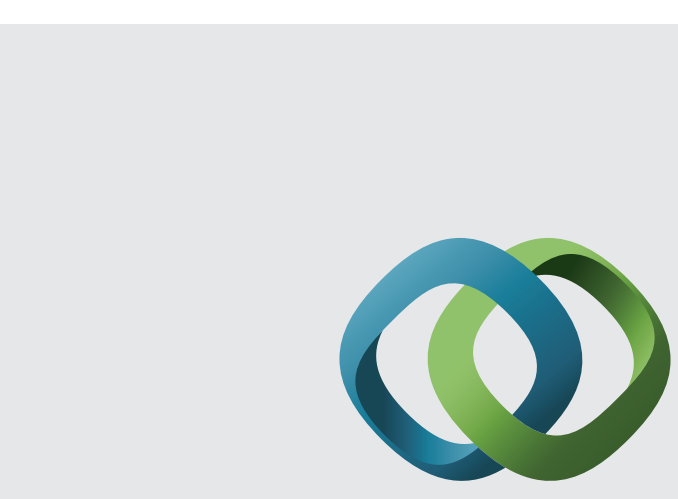

\section{Hindawi}

Submit your manuscripts at

http://www.hindawi.com
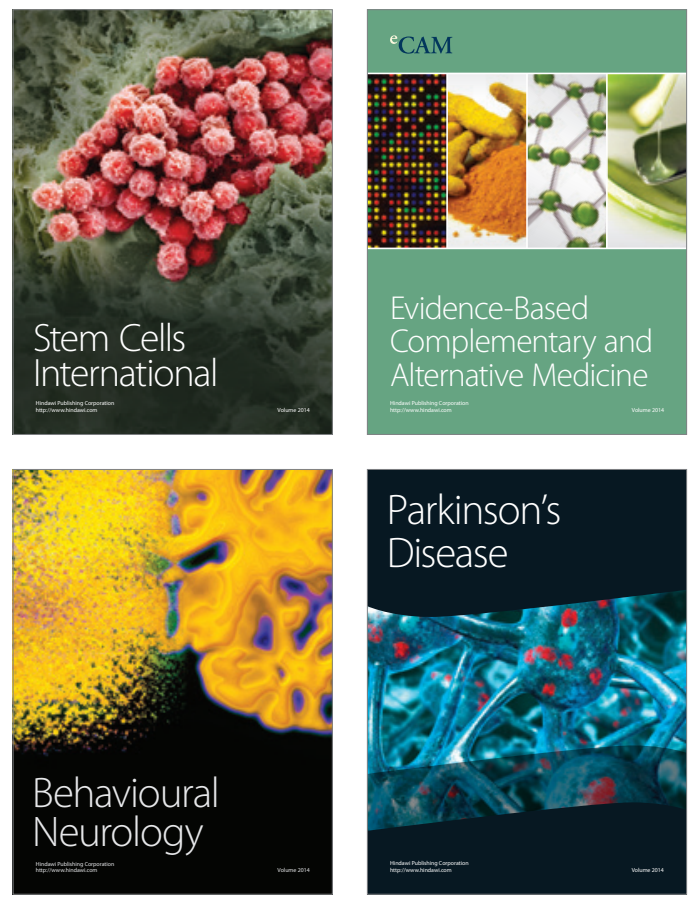
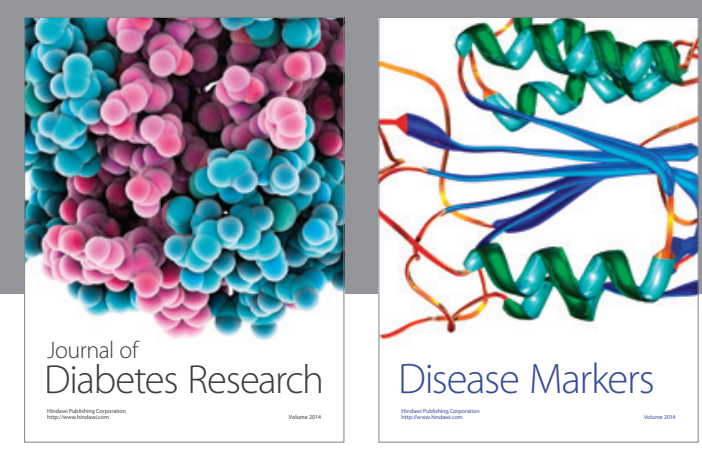

Disease Markers
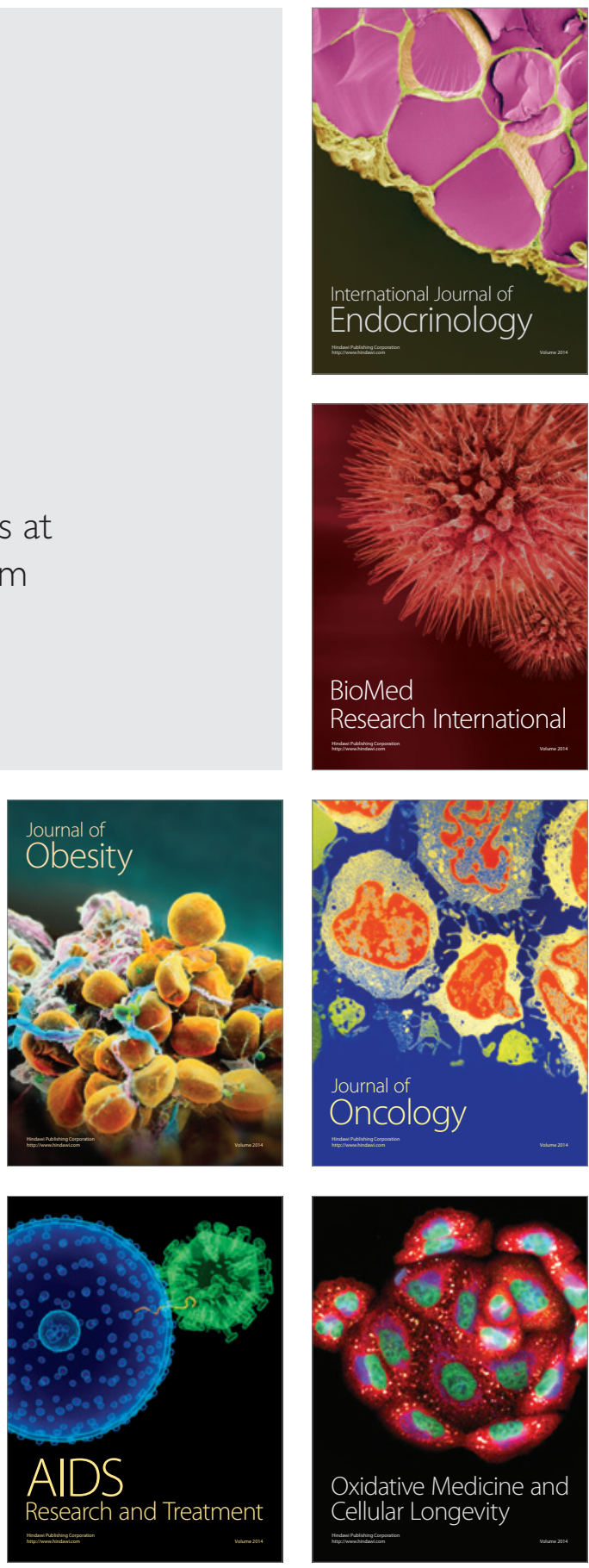